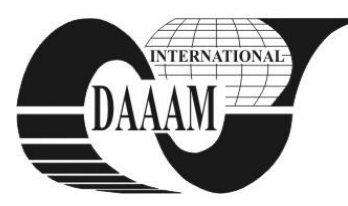

Annals of DAAAM for 2011 \& Proceedings of the 22nd International DAAAM Symposium, Volume 22, No. 1, ISSN 1726-9679 ISBN 978-3-901509-83-4, Editor B. Katalinic, Published by DAAAM International, Vienna, Austria, EU, 2011 Make Harmony between Technology and Nature, and Your Mind will Fly Free as a Bird Annals \& Proceedings of DAAAM International 2011

\title{
WEAR, FRICTION AND TEMPERATURE MONITORING OF POLYPHENYLENE SULPHIDE COMPOSITES UNDER DRY SLIDING REGIME
}

\author{
BESNEA, M[aria] - A[ida] - C[ristina]; TRUFASU, D[an] - C[atalin]; \\ ANDREI, G[abriel] \& DELEANU, L[orena]
}

\begin{abstract}
Two polyphenylene sulphide matrix-based composites were investigated: PPS GF 40 (PPS -polyphenylene sulphide $+40 \%$ glass fibers) and PPS PVX (PPS - polyphenylene sulphide $+10 \%$ PTFE $+10 \%$ carbon fibers $+10 \%$ graphite). The tribological properties of these composites were tested on a Universal Tribometer UMT-2 (CETR) apparatus (pin-on-disc test).
\end{abstract}

Key words: wear, friction, composites, polyphenylene sulphide

\section{INTRODUCTION}

Polyphenylene sulphide is a semicrystalline high performance thermoplastic matrix. Fiber reinforced composites are well known to improved friction and wear performances of the composites (Yu \& Bahadur, 1998). Adding materials like PTFE, carbon fibers and graphite to thermoplastic polymers (Bijwe \& Indumathi, 2004; Zhang et al., 2004; Friedrich et al., 2005) reduce friction and wear of composites as compared to the neat polymer.

\section{EXPERIMENTAL DETAILS AND MATERIALS}

Wear and friction tests were performed on a pin-on-disc machine (Universal Tribometer UMT-2, CETR), where the pin is pressed against a rotating disc. The pin is perpendicularly to the surface of the disc that is horizontally positioned. The disc was made of polymer composite and the pin was made of steel (41MoCr11, HRC 55-58, Sa=0.8 $\mu \mathrm{m}$ ). Both the pin and the disc were cleaned with tensioactive agent before being tested. For each test a new pair pin-disc was used. The tests were performed in dry sliding regime, at the ambient temperature and for a sliding distance of $10 \mathrm{~km}$. The test parameters were: the sliding speed: $0.25,0.5$ and $0.75 \mathrm{~m} / \mathrm{s}$, respectively, the average calculated pressure on the contact pin-disc: $0.25,0.5,0.75 \mathrm{MPa}$, respectively. Here are presented the results for two composites with PPS matrix: PPS GF 40 (PPS $+40 \%$ glass fibers) and PPS PVX (PPS + 10\% PTFE $+10 \%$ carbon fibers $+10 \%$ graphite).

\section{RESULTS AND DISCUSSION}

The composite reinforced with glass fibers (PPS GF 40) presents a dominant abrasive wear manifested by preferential removing of the polymer thus, the glass fibers remain uncovered in time. Because of the higher concentration of fibers, these develop a more intense abrasive wear on the steel pin, where glass fiber chips were found. The noticed brown traces are due to the oxidation products of the polymer on the surface as a result of prolonged contact with air, which allows oxygen to be attached on the molecular chains.

When increasing the average pressure, the friction coefficient is not stable, presenting oscillations at irregular time intervals due to the wear processes occurring at the contact surfaces, such as: adhesive wear (adhesion of the composite on the steel pin), abrasive wear as by removing wear debris the glass fibers remaining uncovered, oxidation wear evidenced by the brown traces at the contact surface of the disc and pin (the transferred film could oxidize also) (Fig. 1).

Figure 2 presents the variation of friction coefficient of PPS PVX. Adding materials like graphite and PTFE induce a lower wear rate due to their transfer to the surfaces and the generation of a film of graphite or/and PTFE on the bodies in contact.

For $v=0.75 \mathrm{~m} / \mathrm{s}$ and $\mathrm{p}=0.5 \mathrm{MPa}$ the friction coefficient slowly increases to the value of 0.20 in the range of $0-2500 \mathrm{~m}$. The friction coefficient values drop after $4500 \mathrm{~m}$, reaching 0.16 with small variations that can be attributed to the irregular distribution of carbon fibers in the composite matrix and the initiation of the transfer film of graphite and PTFE in a nonuniform manner. In time, this process and a more uniform film lead to a stabilization of the friction coefficient around 0.175 , between $7000-10000 \mathrm{~m}$. There is a decrease in the friction coefficient with increasing the sliding speed. Due to its low surface energy and poor creep resistance, PTFE can be easily pulled out from the matrix to form a continuous transfer film. The thermographic camera has recorded the thermal field at three points on the disc: the first point of contact was set behind the contact between the pin and the disc (AR01), the second point was the point of contact between pin and disc (AR02) and the last point was a diameterly opposite contact point (AR03) (Fig. 3). Composites with graphite induce good thermal conductivity and due to this the contact temperature is quite low (Yu \& Bahadur, 1998; Friedrich et al., 2005). The temperature in contact beeing low there is no softening or melting of the superficial layer of the composite.

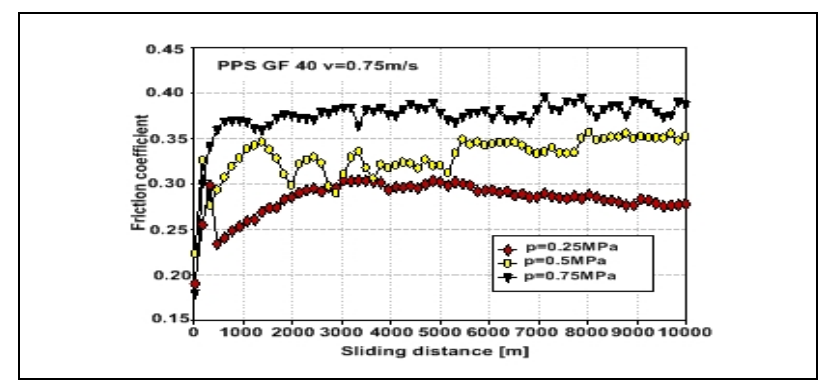

Fig. 1 The friction coefficient for pin-on-disc test, depending on the sliding distance

With increasing of the friction coefficient, the temperature rises in all the three studied points, the evolution of the temperature having a similar form as that of the friction coefficient (compare Fig. 1 to Fig. 4 and Fig. 2 to Fig. 5).

The temperature at the contact boundary (AR01) for the composite containing PTFE and graphite is lower, also because the heat generated by friction is lower. The friction coefficient evolution can be divided into four stages according to Czichos (Czichos \& Habig, 2010) : the first stage (0-2000 m) where the friction coefficient increased from the minimum values of the test beginning, the second stage reaching the maximum value of 0.25 , for $\mathrm{v}=0.75 \mathrm{~m} / \mathrm{s}$, and a contact boundary temperature of $\sim 39^{\circ} \mathrm{C}$. The third stage $(2000-5000 \mathrm{~m})$ corresponds to a decrease of friction coefficient with transfer film formation, 
PTFE, graphite and broken carbon fibers partially becoming wear debris. The stage between $5000-10000 \mathrm{~m}$ is a steady state.

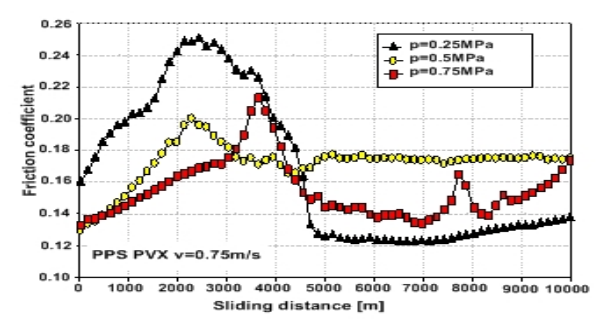

Fig. 2 The friction coefficient for the pin-on-disc test, depending on the sliding distance

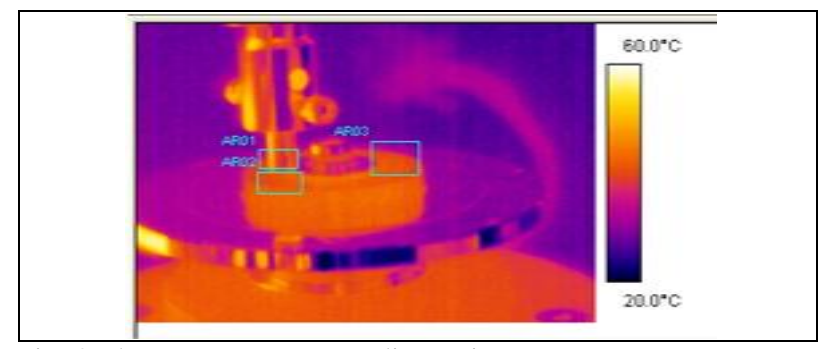

Fig. 3 The temperature recording points

For the composite reinforced with $40 \%$ glass fibers, the contact temperature increases with the increase of the friction coefficient. The difference between the temperature at the contact boundary and the temperatures recorded in the other two points is only of about $2-4^{\circ} \mathrm{C}$ (Fig 5.).

The wear of each disc was calculated using the mass loss of the composite disc and the specific wear rate was calculated with the following relation:

$$
W_{s}=\Delta m /\left(\rho d F_{N}\right)\left[\mathrm{mm}^{3} /(\mathrm{Nm})\right]
$$

where $\Delta m=m_{i}-m_{f} ; \Delta m$ - the wear as mass loss [g]; $m_{i}, m_{f}$ the initial mass, the mass of the disc after being tested, respectively $[\mathrm{g}] ; \rho-$ the density of the material $\left[\mathrm{g} / \mathrm{mm}^{3}\right] ; d-$ the sliding distance $[\mathrm{m}] ; F_{N}-$ the normal force $[\mathrm{N}]$

For the composite reinforced with glass fibers, tested at $\mathrm{p}=0.25 \mathrm{MPa}$ the lowest wear rate was recorded, $1.1 \times 10^{-6}$ $\mathrm{mm}^{3} /(\mathrm{Nm})$ and increases with increasing the average pressure. A maximum wear rate was evidenced between the tested values of $0.5 \mathrm{~m} / \mathrm{s}$ and $0.75 \mathrm{~m} / \mathrm{s}$ (Fig. 6).

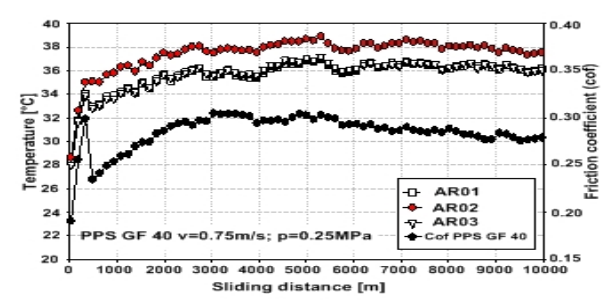

Fig. 4 The evolution of thermal field and friction coefficient developed during the pin-on-disc test (PPS GF 40)

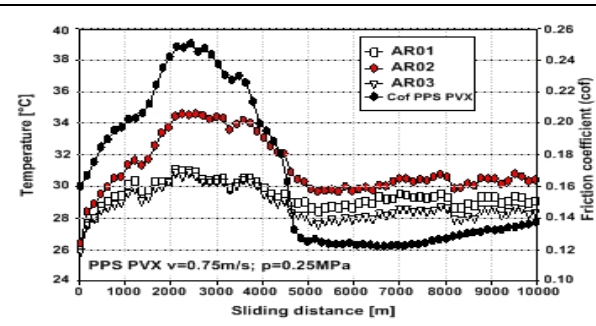

Fig. 5 The evolution of thermal field and friction coefficient developed during the pin-on-disc test (PPS PVX)
For PPS PVX composite, a minimum wear rate of $3.1 \times 10^{-6}$ $\mathrm{mm}^{3} /(\mathrm{Nm})$ was registered for an average pressure of $0.5 \mathrm{MPa}$ and the sliding speed $0.5 \mathrm{~m} / \mathrm{s}$. The wear behaviour takes into account the homogeneous transfer film of graphite and PTFE on the steel pin, which protects the composite surface from the roughness surface of the steel pin and thus, wear rate of the composite decreases.

The generation of a more homogeneous solid lubricating transfer film is controlled mainly by the phenomenon of plasticization at high loads of the graphite and PTFE (Fig. 7).

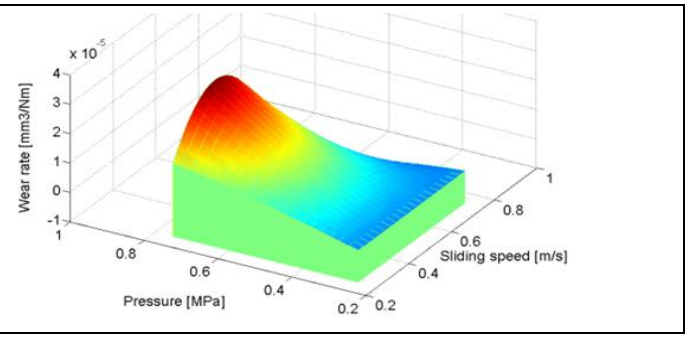

Fig. 6 The evolution of specific wear rate for experimental pinon-disc test (PPS GF 40)

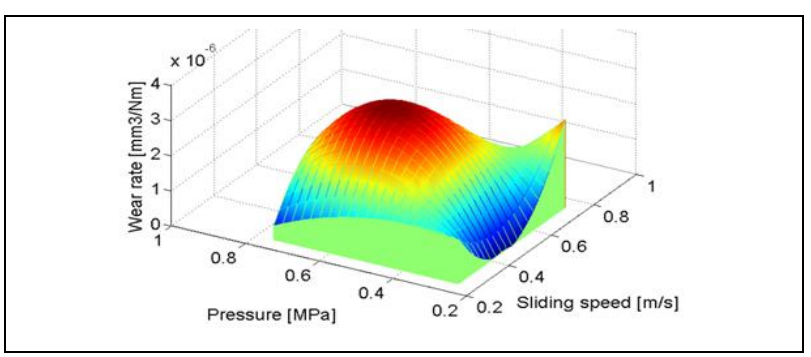

Fig. 7 The evolution of specific wear rate for pin-on-disc test (PPS PVX)

\section{CONCLUSION}

PPS PVX composite has shown a better tribological behaviour (wear rate and friction coefficient) in the range of test conditions, as compared to PPS GF 40 composite.

Temperature monitoring revealed a good correlation between friction coefficient, wear rate and thermal regime.

\section{ACKNOWLEDGEMENTS}

The work of Aida Besnea and Dan Trufasu was supported by Project SOP HRD - SIMBAD 6853, 1.5/S/15 - 01.10.2008

\section{REFERENCES}

Yu, L. \& Bahadur, S. (1998). An investigation of the transfer film characteristics and the tribological behaviors of polyphenylene sulfide composites in sliding against tool steel. Wear, Vol. 214, No. 2, (February 1998) 245-251, ISSN: 0043-1648

Bijwe, J. \& Indumathi, J. (2004). Influence of fibres and solid lubricants on low amplitude oscillating wear of polyetherimide composites. Wear, Vol. 257, No. 5-6, (September 2004) 562-572, ISSN 0043-1648.

Zhang, Z.; Breidt, C.; Chang, L. \& Friedrich, K. (2004). Wear of PEEK composites related to their mechanical performances. Tribology International, Vol. 37, No. 3, (March 2004) 271-277, ISSN 0301-679X

Friedrich, K.; Zhang, Z. \& Alois K. Schlarb (2005). Effects of various fillers on the sliding wear of polymer composites wear. Composite Science and Technology, Vol. 65, No. 1516, (December 2005) 2329-2343, ISSN 0266-3538

Czichos, H. \& Karl-Heinz Habig, (2010). Tribologie Handbuch, Vieweg+Teubner Verlag, ISBN 978-3-83480017-6, Germany 